\title{
Adaptation Strategies of Farm Animals to Water Shortage in Desert Areas
}

\author{
Tewodros Alemneh ${ }^{1 *}$ and Dawit Akeberegn ${ }^{2}$ \\ ${ }^{1}$ Woreta Town Office of Agriculture and Environmental Protection, Ethiopia \\ ${ }^{2}$ Debre Berhan City Municipality Office, Meat Inspection \& Hygiene, North Shewa, Ethiopia
}

*Corresponding author: Tewodros Alemneh, Woreta Town Office of Agriculture and Environmental Protection, South Gondar Zone, Amhara Regional State, Ethiopia.

To Cite This Article: : Tewodros Alemneh and Dawit Akeberegn. Adaptation Strategies of Farm Animals to Water Shortage in Desert Areas. Am J Biomed Sci \& Res. 2019 - 2(6). AJBSR.MS.ID.000617. DOI: 10.34297/AJBSR.2019.02.000617

Received: April 01, 2019 | Published: May 06, 2019

\begin{abstract}
This review is an attempt to collate and retrieve information pertaining to farm animal adaptation to water shortage in desert areas. Livestock play an important role in the global economy. Climate change, especially heat stress in water shortage areas, appears to be the major factor that negatively influences the production, reproduction and growth of livestock. The adverse impacts of heat stress on these productive functions depend on species and breed differences and the magnitude of this impact determines the adaptive potential of the animals. Livestock responds to the changing environments by altering their phenotypic and physiological characters. Among these characters; physiological response, morphological response, blood biochemical response, neuroendocrine response, molecular and cellular response, metabolic response, and behavioral responses are the major ones. Physiological responses include alterations in body temperature, respiration rate, heart rate and skin temperature. Blood biochemical and endocrine responses are by which the animals try to cope up to adverse environmental conditions by altering the concentration of blood metabolites, stress, and metabolic hormones under the control of the nervous system. Cellular and molecular responses are the cardinal mechanisms by which the animal survives heat stress.
\end{abstract}

Keywords: Livestock; Water shortage; Farm animals; Adaptation

\section{Introduction}

Climate change is rapidly emerging as a global critical development issue affecting many sectors in the world and is considered to be one of the most serious threats to sustainable development [1]. Among the environmental variables affecting animals, heat stress is one of the factors making animal production challenging in many parts of the world [2]. Although animals can adapt to climatic stressors, the response mechanisms that ensure survival are also detrimental to performance). The vulnerability of livestock to heat stress varies according to species, genetic potential, life stage, management or production system and nutritional status [3]. Moreover, under the testing environmental conditions animal productivity is affected resulting in economic losses for livestock industries. It is important that efforts to understand the adaptive responses of the domestic livestock are taken.

Agriculture is the economic mainstay in most African countries, except in population depending on the sector for their livelihood [4]. In most African countries, crop farming is mainly subsistence and rain-fed, but due to climate change frequent and untimely raining affects harvest of produce and thus, food production. This makes Africa particularly vulnerable to the impacts of climate change. The vulnerability of the region is further worsened by the fact that the climate is already too hot as it is tropical in nature [1].

Heat stress affects the growth performance [5], milk production [3], reproductive performance [6], meat production [7] and disease occurrences [8]. The adverse impacts of heat stress on these productive functions depend on species and breed differences and the magnitude of this impact determines the adaptive potential of the animals [2]. This review is an attempt to collect and retrieve information pertaining to farm animal adaptation to water shortage in desert areas.

\section{General Information on Adaptation}

\section{What is Adaptation of Animals?}

Anything that helps an organism survives in its environment is an adaptation. Adaptation also refers to organisms' ability to adjust to various conditions within its environment. Examples: 
change in size of bird's beak, development of sharp teeth and claws, etc. [9]. The adaptation of animals to their environment is a series of varied biological processes with varying purposes, but the general purpose is the continued survival of the species. This is a key to the difference between an animal's adaptation and ability. Many animals are able to engage in certain behaviors which have no discernible function and may not be a part of adaptation. The human animal is probably the best example of a living thing which has incredible diversity in behavior, yet not all of it is beneficial to species survival. In many cases, it is quite the contrary [10]. As stated above, behavioral changes are not the only processes in which animals take par as a form of adaptation. It is neither solely behavior nor physical characteristics which allow animals to adapt to their environments. In a Dictionary of Science from Oxford University Press it is defined as "any change in the structure or functioning of successive generations of a population that makes it better suited to its environment" [11]. This means it is not just any physical trait or behavior. It has a purpose and that purpose is to survive [10].

\section{Adaptation Strategies of Farm Animals to Water Shortage in Desert Areas}

All living beings need to adapt to their environment to survive. These environments are as wide ranging as life itself, whether underwater, in a desert or even in the body of another living being [10]. There several phenotypic and genotypic characters which impart the adaptive potential to an animal, thereby allowing it to cope with harsh conditions [2]. These adaptive mechanisms help animals survive in a particular environment. Basically, animal adaptation involves morphological, behavioral and genetic capacity of the animal for change. These may arise over generations through slow modify captions as animals adapt to environmental challenges. The adaptation mechanisms which are listed by various authors are discussed below [2].

Physiological Adaptations: These types of adaptations are related to changes in the metabolism of different organisms. Some organs in an animal body function differently when certain changes occur in the environment. The two most well-known physiological adaptations are hibernation and estivation [2]. These are two different types of inactivity where the metabolic rate slows down so much that the animal can survive without eating or drinking anything [10]. In both cases, temperature is usually a factor. While we often think of bears hibernating for the winter, it is not only when the temperature is low that these processes occur. When the temperature is below $0^{\circ} \mathrm{C}$ or is above $40^{\circ} \mathrm{C}$ and there is a relatively low humidity, certain animals can lower their basal metabolic rate for serious amounts of time (Ibid) [2].

Behavioral Adaptations: Behavioral adaptation is recognized as the first and foremost response adopted by animals to reduce heat load [12]. One of the most quick and profound behavioral changes seen in heat stressed animals is shade seeking. The stressed animals attempt to ameliorate the negative effects of direct heat load by using shade whenever they can access to it. Research clearly shows that dairy cattle use shade in warm environments, and that the frequency of this behavior was found to increase with higher air temperature and solar radiation [13]. However, tropical indigenous breeds were observed to be highly adapted to direct heat stress, spending more time for grazing than resting in shade [10].

These adaptations lead the animals to develop certain behavioral characteristics to survive the individual or the species. Fleeing from a predator, hiding during sleep, seeking refuge from climate issues or moving to find different food sources are all behavioral adaptations [10]. The two most characteristic forms of behavioral adaptations are probably migration and courtship. Migration allows the animals to find better resources or evade threat. Courtship is a set of behavioral patterns with the desired result of finding a mate and reproducing [2].

Morphological Response: Morphological traits in livestock are highly important from the adaptation point of view, as they directly influence the heat exchange mechanisms (cutaneous convection, radiation and evaporation) between the animal and the surrounding environment [14]. Breed differences for morphological adaptive traits are evident in some species (Ibid). Coat color was one of the important morphological traits which impart adaptive ability to heat stressed livestock. For example, light-/white colored coats in animals are recognized as being advantageous in hot tropical regions as it reflects $50 \%$ to $60 \%$ of direct solar radiation compared with the dark-colored animals (Ibid). Highly pigmented skin protects the deep tissues from direct short-wave UV radiation by blocking its penetration. In addition, coat length, thickness and hair density also affect the adaptive nature of animals in tropical regions, where short hair, thin skin and fewer hair follicles per unit area are directly linked to higher adaptability to hot conditions. Indigenous sheep breeds adapted to arid and semi-arid regions possess morphological characteristics such as carpet type wool, which helps to provide better protection from direct solar radiation, and this type of wool also allows effective cutaneous evaporative heat dissipation [15]. The fat tail observed in sheep is also recognized as a morphological adaptation for better heat transfer [16].

Coetaneous evaporation is recognized as the most important mode of heat dissipation in cattle. Thus, higher diameter, volume, perimeter and density of sweat gland in animals are considered to be good adaptive traits for hot environments [17]. Smaller body size of tropical indigenous cattle breeds (as compared with English and European cattle) is recognized as being beneficial for surviving in harsh environments, due in part to the smaller animals' lower feed and water requirements. These mechanisms help the animals to survive the heat stress challenges. In addition, cattle breeds that are indigenous to the tropical regions also possess efficient testicular thermoregulatory mechanisms during heat stress conditions through higher ratios of testicular artery length and volume to the volume of testicular tissue [18].

Neuro-endocrine Response: Hormones, specifically those produced from the adrenal and thyroid glands, are recognized as having a significant role in thermoregulation and metabolic adjustments in animals, particularly in hot environments. The hypothalamo-pituitary-adrenal axis (HPA axis) acts as one of 
the principal endocrine regulators of the stress responses. The products of HPA axis which control stress pathway in animals are corticotropin-releasing hormone (CRH), ACTH and cortisol. The activation of the HPA axis may lead to enhanced production and release of cortisol into circulation; cortisol is the primary stress hormone of ruminants [19]. Several studies of various livestock species clearly established higher plasma cortisol level in ruminants during heat stressed conditions [20]. Further, the plasma aldosterone level in heat stressed Osmanabadi goats was reported to be higher as compared with the normal conditions and when they had adlibitum water access [12]. Aldosterone is a steroid hormone released from the cortex of the adrenal glands and is involved in the regulation of water and mineral balance in the body. It is a well-established fact that during heat stress conditions ruminants may undergo severe dehydration, which may result in the activation of renin-angiotensin-aldosterone pathway to restore the water and electrolyte balance [12].

In a similar study in Malpura rams, Sejian et al. [2] reported that the plasma cortisol level was significantly lower in multiple stressors groups (heat, nutrition and walking) as compared with individual (heat stress/nutritional stress) or combined stresses (heat and nutrition stress). This was in contrast to the findings of Shilja et al. [12] using Osmanabadi goats wherein they reported significantly higher plasma cortisol concentration in multiple stresses (heat and nutritional stress) group as compared with the individual stress (heat/nutrition) group. This suggests that goats are better able to cope with the multiple stressors than sheep. Severe dehydration may lead to increased secretion of antidiuretic hormone (ADH) through activation of renin-angiotensinaldosterone system. Higher levels of circulating ADH hormone level were reported in crossbred goats under severe dehydration [21]. The ADH hormone regulates the blood osmolarity by increasing the water absorption in the kidneys, which also assists the excretion of concentrated urine in animals suffering from heat stress (Ibid). Further, sympathetic adrenal medullary system also contributes enormously for controlling stress activities primarily through the release of catecholamines in animals [21].

Blood Biochemical Response: There are several reports which showed a varying trend of total blood haemoglobin $(\mathrm{Hb})$ with an increase in environmental temperature. Haque et al. [22] observed a significant rise in total blood $\mathrm{Hb}$ concentration at $40^{\circ} \mathrm{C}$, $42^{\circ} \mathrm{C}$ and $45^{\circ} \mathrm{C}$ as compared with $22^{\circ} \mathrm{C}$ in both young and adult heat stressed Murrah buffaloes. They attributed this increase to haemoconcentration so that the animals could meet a higher oxygen requirement during stressful conditions. An elevated value of $\mathrm{Hb}$ was also established in thermal stressed southern Nigeria dwarf goats and the observed change may be attributed to higher $\mathrm{Hb}$ requirement in the animal to meet the increased oxygen circulation during panting [23]. A higher value of total blood $\mathrm{Hb}$ concentration was also observed in lactating Surti buffaloes during a hot dry period compared with a hot humid period, and that the increased $\mathrm{Hb}$ was correlated to severe dehydration [24].

Plasma haptoglobin has been observed to rise in dairy cows during high ambient temperatures [25]. Haptoglobin is one of the most commonly used acute phase proteins to assess the health and inflammatory response of animals [26]. Alberghina et al. [25] reported a significantly higher production of haptoglobin in the blood plasma of Holstein-Frisian dairy cows exposed to high heat load.

In several experiments, significantly increased levels of packed cell volume (PCV) were observed in various livestock species suffering from heat stress $[14,27]$. However, a decreased concentration of plasma protein [28,29] and cholesterol [29] were recorded in livestock exposed to elevated ambient temperatures. Further, there are reports which also established an increased concentration of free fatty acid in livestock exposed to heat stress [30]. Antioxidant enzymes such as superoxide dismutase (SOD) and glutathione peroxidase (GPx) are synthesized in the body and provide protection from reactive oxygen species generated during heat stress [31]. These antioxidants scavenge both intracellular and extracellular super oxides and inhibit lipid peroxidation of plasma membrane [32]. Chaudhary et al. [24] reported a significantly higher level of plasma malondialdehyde, SOD and GPx activities in Surti buffaloes during hot humid periods and hot dry periods indicating an increased free radical production during periods of heat stress. In addition to this, plasma antioxidant levels in the hot dry period were significantly higher than in the hot humid period indicating more stressful condition may lead to the elevated synthesis of free radicals (Ibid). Likewise, Kumar et al. [33] also reported a significant increase in SOD activity in Beetal goats during summer. There are also reports establishing significantly higher TAS values in a hot dry season in ruminant animals $[24,30]$. All these findings establish the significance of blood biochemical responses to be one of the primary means used by animals to cope with adverse environmental conditions.

Metabolic Responses: Metabolic adaptation is considered to be one of the important means through which animals tackle heat stress challenges, essentially by reducing the metabolic heat production [34]. Thyroid hormones play an important role in regulating the thermogenesis and are also identified as an indicator for assessing the thermo-tolerance of the farm animals [35]. Thyroid hormones, namely triiodothyronine (T3) and thyroxine (T4), play a vital role in metabolic adaptation and growth performance of animals [26]. During heat stress, serum and plasma concentrations of $\mathrm{T} 3$ and $\mathrm{T} 4$ reduce and are likely to be due to the direct effect of heat stress on the hypothalamo pituitary and thyroid axis to decrease the production of thyrotropin releasing hormone, which will limit basal metabolism [34]. In a recent study conducted using three indigenous goat breeds during summer, it was concluded that $\mathrm{T} 3$ could serve as an indicator of metabolic activity in animals (Ibid). Reduced concentrations of circulating $\mathrm{T} 3$ and T4, indicative of an attempt to reduce metabolic rate and thus metabolic heat production in heifers [36], sheep [37] and goat [35], have been reported. However, contrary results showing no significant alterations in the metabolic hormonal levels have also been reported recently in three indigenous breeds of goats [34]. The authors suggest that this is due to the superior adaptive capability of the animals to the hot tropical climate. On comparative 
basis, the effect of multiple stressors on plasma T3 and T4 was not severe in Osmanabadi goats as only T4 differed between the control and multiple stress groups; whereas in the sheep study, the severity of multiple stresses were of higher magnitude on plasma thyroid hormone levels with much lower levels of both T3 and T4 concentration [2]. This again points towards the better adaptive mechanisms in goats as compared with sheep at least for multiple stressor exposure.

Cellular and Molecular Responses: Heat stress was found to alter several molecular functions such as DNA synthesis, replication and repair, cellular division and nuclear enzymes and DNA polymerases functions [38]. Further, it was shown that heat stress affects both the fluidity and the stability of cellular membranes and inhibits receptors as well as trans-membrane transport proteins function (Ibid). Heat stress also induces multiple variations in to skeleton organization, including the cell form, the mitotic apparatus and the intra cytoplasmic membranes such as endoplasmic reticulum and lysosomes. Heat stress elicits a complex array of cellular and molecular responses in livestock [39]. With the development of molecular biotechnologies, new opportunities are available to characterize gene expression and identify key cellular responses to heat stress [40]. For example, there are changes in the expression patterns of certain genes that are fundamental for thermo-tolerance at the cellular level in animals [31]. Such genes having a cellular adaptation function in animals are considered potential biomarkers for understanding stress adaptation mechanisms [41].

The classical heat shock protein (HSP) genes, apoptotic genes and other cytokines and toll-like receptors are considered to be up regulated on exposure to heat stress. Several reports Heat stress and livestock adaptation established the role of HSP70 during heat stress exposure in ruminant livestock and they identified this to be ideal molecular marker for quantifying heat stress response [12, 41]. Apart from this, several other genes such as SOD, nitric oxide synthase (NOS), thyroid hormone receptor (THR) and prolactin receptor (PRLR) genes were found to be associated with thermotolerance in ruminant livestock [41]. Furthermore, Shilja et al. [12] reported a higher expression of HSP70 messenger RNA (mRNA) in the adrenal gland of the multiple stressor groups, which could be attributed to the adaptive mechanism of Osmanabadi goats to counter both the heat stress and nutritional stress.

The significantly higher expression of adrenal HSP70 in the multiple stressed animals as compared with animals subjected only to heat stress could be attributed to additional nutritional stress in the multiple stresses group. The higher HSP70 expression in the adrenal gland could also be attributed to the hyperactivity of adrenal cortex to synthesize more cortisol as evident from this study. Similarly, the plasma HSP70 and expression pattern of peripheral blood mononuclear cell HSP70 also showed similar trends of significantly higher value in multiple stressor group animals as compared with control and individual (heat/nutritional) stress groups (Ibid) [12].

Epigenetic regulation of gene expression and thermal imprinting of the genome could also be an efficient method to improve thermal tolerance in livestock [40]. At the molecular level, epigenetic changes are mediated by changes to the chromatin conformation initiated by DNA methylation, histone variants, post-translational modifications of histones and histone inactivation, non-histone chromatin proteins, non-coding RNA and RNA interference [42]. Deoxyribonucleic acid methylation is a well-studied epigenetic regulatory mechanism that plays a key role in the regulation of gene expression. Heat stress was found to influence the DNA methylation pattern in pigs [39]. Further, these authors also established that HSP70s and their associated cochaperones participate in numerous processes essential to cell survival under stressful conditions. They assist in protein folding and translocation across membranes, assembly and disassembly of protein complexes, presentation of substrates for degradation and suppression of protein aggregation (Ibid). The above discussion clearly point towards the influence of both the genetic and epigenetic changes altering the thermotolerant gene expression and therefore, both these factors should be taken into account when formulating breeding programmes for changing environmental conditions.

Limits to Animal Adaptation: Animal adaptations are various and extensive. They allow species to survive, but eventually something will come along to replace them. This is due to the limits of their adaptive abilities. However, many adaptations are not being allowed to happen naturally as humans are exerting such an influence in the world that they bypass natural selection [10].

A report in 2012 from the Royal Society shows that numbers of a species are keys in their success of adaptation as does a range of genetic variation [43]. Since humans have killed so many animals to near extinction, many species struggle to return their species to the numbers they once enjoyed. Also, the hazardous effects of climate change are making it difficult for animals to adapt in time to the rapidly changing environment. Animal adaptations are various and extensive. They allow species to survive, but eventually something will come along to replace them. This is due to the limits of their adaptive abilities. However, many adaptations are not being allowed to happen naturally as humans are exerting such an influence in the world that they bypass natural selection (Ibid) [10].

\section{Conclusion}

Environmental factors are the primary factors influencing livestock production in the changing climatic condition. Environmental stresses reduce production parameters like growth, milk yield, and reproduction in livestock leading to severe economic constraints. Livestock possess a wide range of adaptive mechanisms such as physiological, morphological, biochemical, endocrine, cellular and molecular responses to cope up with environmental challenges. However, while doing so their productive potential is compromised. To reduce the economic burden on farmers as a result of environmental stresses, strategies need to be developed with multidisciplinary approach to reduce the adverse effects of environmental stresses negatively impacting livestock production. Effects are equally needed to further understand the hidden intricacies of molecular, cellular and other mechanisms of livestock adaptation as this might pave way for developing suitable amelioration strategies. Animal adaptations allow species to 
survive, but eventually something will come along to replace them. This is due to the limits of their adaptive abilities. However, many adaptations are not being allowed to happen naturally as humans are exerting such an influence in the world that they bypass natural selection.

\section{Acknowledgement}

Author's deepest gratitude goes to members of Department of Animal Sciences, College of Agriculture and Natural Resources Science, and the communities of Debre Berhan University.

\section{Conflicting of Interests}

Authors declare that no any conflicting of interest in the publication of this work.

\section{References}

1. Akinnagbe O M, Irohibe I J (2018) Agricultural Adaptation Strategies to Climate Change Impacts in Africa: A Review.

2. Sejian V, Bhatta R, Gaughan B, Dunshea R, Lacetera N (2018) Review: Adaptation of animals to heat stress. National Institute of Animal Nutrition and Physiology 12(s2): s431-s444.

3. Das R, Sailo L, Verma N, Bharti P, Saikia J, et al. (2016) Impact of heat stress on health and performance of dairy nimals: A review. Vet World 9(3): 260-268.

4. Organization for Economic Cooperation and Development (OECD) (2009) Annual Report. The Public Affairs Division, Public Affairs and Communication Directorate pp. 1-130.

5. Baumgard L H, Rhoads R P, Rhoads M L, Gabler N K, Ross J W, et al. (2012) Impact of climate change on livestock production. In Environmental stress and amelioration in livestock production pp. 413-468.

6. Rhoads M L, Rhoads R P, VanBaale M J, Collier R J, Sanders S R, et al. (2009) Effects of heat stress and plane of nutrition on lactating Holstein cows: I. Production, metabolism, and aspects of circulating somatotropin. Journal of Dairy Science 92(5): 1986-1997.

7. Archana PR, Sejian V, Ruban W, Bagath M, Krishnan G, et al. (2018). Comparative assessment of heat stress induced changes in carcass traits, plasma leptin profile and skeletal muscle myostatin and HSP70 gene expression patterns between indigenous Osmanabadi and Salem Black goat breeds. Meat Sci 141: 66-80.

8. Rojas Downing MM, Nejadhashem AP, Harrigan T, Woznicki SA (2017) Climate change and livestock: impacts, adaptation, and mitigation. Climate Risk Management 16: 145-163.

9. Schoolwork Editorial Team (SET) (2017) What is Adaptation? Types of Adaptations. School Work Helper.

10. Turner F Josie (2018) Types of Adaptations in Animals. Journalist.

11. Oxford Dictionary of Science (2019) Meaning of Adaptation. Oxford University Press, UK.

12. Shilja S, Sejian V, Bagath M, Manjunathareddy GB, Kurien EK, et al. (2017) Summer season related heat and nutritional stresses on the adaptive capability of goats basedon blood biochemical response and hepatic HSP70 gene expression. Biological Rhythms Research 48(1): 65-83.

13. Curtis AK, Scharf B, Eichen PA, Spiers DE (2017) Relationships between Ambient Conditions, Thermal status, and Feed Intake of Cattle during Summer Heat Stress with Access to Shade. J Therm Biol 63: 104-111.

14. McManus CM, Paludo GR, Louvandini H, Gugel R, Sasaki LCB, et al. (2009) Heat tolerance in Brazilian sheep: physiological and blood parameters. Tropical Animal Health Production 41(1): 95-101.

15. Mahgoub O, Kadim IT, Al Dhahab A, Bello RB, Al-Amri IS, et al. (2010) An assessment of Omani native sheep fiber production and quality characteristics. Journal of Agricultural and Marine Sciences 15: 9-14.
16. Gootwine E (2011) Mini review: breeding Awassi and Assaf sheep for diverse management conditions. Tropical Animal Health and Production 43(7): 1289-1296.

17. Jian W, Ke Y, Cheng L (2016) Physiological responses and lactation to cutaneous evaporative heat loss in Bos indicus, Bos taurus, and their crossbreds. Asian Australasian Journal of Animal Sciences 28(11): 15581564.

18. Brito LF, Silva AE, Barbosa RT, Kastelic JP (2004) Testicular thermoregulation in Bos indicus, crossbred and Bos taurus bulls: relationship with scrotal, testicular vascular cone and testicular morphology, and effects on semen quality and sperm production. Theriogenology 61(2-3): 511-528.

19. Binsiya TK, Sejian V, Bagath M, Krishnan G, Hyder I, et al. (2017) Significance of hypothalamic-pituitary-adrenal axis to adapt to climate change in livestock. International Research Journal of Agricultural and Food Sciences 2(1): 1-20.

20. Wojtas K, Cwynar P, Kolacz R (2014) Effect of thermal stress on physiological and blood parameters in Merino sheep. Bulletin of the Veterinary Institute in Pulawy 58(2): 283-288.

21. Kaliber M, Koluman N, Silanikove N (2016) Physiological and behavioral basis for the successful adaptation of goats to severe water restriction under hot environmental conditions. Animal 10(1): 82-88.

22. Haque N, Ludri A, Hossain SA, Ashutosh M (2013) Impact on hematological parameters in young and adult Murrah buffaloes exposed to acute heat stress. Buffalo Bulletin 3: 321-326.

23. Okoruwa MI (2014) Effect of heat stress on thermoregulatory, live bodyweight and physiological responses of dwarf goats in southern Nigeria. European Science Journal 10: 255-264.

24. Chaudhary SS, Singh VK, Upadhyay RC, Puri G, Odedara AB, et al. (2015) Evaluation of physiological and biochemical responses in different seasons in Surti buffaloes. Veterinary World 8: 727-731.

25. Alberghina D, Piccione G, Casella S, Panzera M, Morgante M, et al. (2013) The effect of the season on some blood metabolites and haptoglobin in dairy cows during postpartum period. Archives Animal Breeding 56: 354-359.

26. Aleena J, Pragna P, Archana PR, Sejian V, Bagath M, et al. (2016) Significance of metabolic response in livestock for adapting to heat stress challenges. Asian Journal of Animal Sciences 10: 224-234.

27. Rana MS, Hashem MA, Sakib MN, Kumar A (2014) Effect of heat stress on blood parameters in indigenous sheep. Journal of Bangladesh Agriculture 12: 91-94.

28. Khalek TMMA (2007) Thermoregulatory responses of sheep to starvation and heat stress conditions. Egyptian Journal of Animal Production 44(2): 137-150.

29. Hooda OK, Upadhyay RC (2014) Physiological responses, growth rate and blood metabolites under feed restriction and thermal exposure in kids. Journal of Stress Physiology and Biochemistry 10: 214-227.

30. Chaiyabutr N, Boonsanit D, Chanpongsang S (2011) Effects of cooling and exogenous bovine somatotropin on hematological and biochemical parameters at different stages of lactation of crossbred Holstein Friesian cow in the tropics. Asian-Australasian Journal of Animal Sciences 24(2): 230-238.

31. Gupta M, Kumar S, Dangi SS, Jangir BL (2013) Physiological, biochemical and molecular responses to thermal stress in goats. International Journal of Livestock Research 3(2): 27-38.

32. Zhang H, Yin M, Huang L, Wang J, Gong L, et al. (2017) Evaluation of the cellular and animal models for the study of antioxidant activity: a review. Journal of Food Science 82(2): 278-288.

33. Kumar BVS, Singh G, Meur SK (2010) Effects of addition of electrolyte and ascorbic acid in feed during heat stress in buffaloes. Asian-Australasian Journal of Animal Science 23(7): 880-888. 
34. Pragna P, Sejian V, Soren NM, Bagath M, Krishnan G, et al. (2018). Summer season induced rhythmic alterations in metabolic activities to adapt to heat stress in three indigenous (Osmanabadi, Malabari and Salem Black) goat breeds. Biological Rhythm Research 49(4): 551-565.

35. Todini L (2007) Thyroid hormones in small ruminants: effects of endogenous, environmental and nutritional factors. Animal 1(7): 9971008.

36. Pereira AM, Baccari F, Titto EA, Almeida JA (2008) Effect of thermal stress on physiological parameters, feed intake and plasma thyroid hormones concentration in Alentejana, Mertolenga, Frisian and Limousine cattle breeds. International Journal of Biometeorology 52(3): 199-208.

37. Indu S, Sejian V, Kumar D, Pareek A, Naqvi SMK (2015) Ideal proportion of roughage and concentrate required for Malpura ewes to adapt and reproduce under semi-arid tropical environment. Tropical Animal Health and Production 47(8): 1487-1495.

38. Slimen B, Najar T, Ghram A, Abdrrabba M (2016) Heat stress effects on livestock: molecular, cellular and metabolic aspects, a review. Journal of Animal Physiology and Animal Nutrition 100(3): 401-412.
39. Hao Y, Feng Y, Yang P, Cui Y, Liu J, et al. (2016) Transcriptome analysis reveals that constant heat stress modifies the metabolism and structure of the porcine longissimus dorsi skeletal muscle. Molecular Genetics and Genomics 291(6): 2101-2115.

40. Renaudeau D, Collin A, Yahav S, de Basilio V, Gourdine JL, et al. (2012) Adaptation to hot climate and strategies to alleviate heat stress in livestock production. Animal 6(5): 707-728.

41. Collier RJ, Gebremedhin K, Macko AR, Roy KS (2012) Genes involved in the thermal tolerance of livestock. In Environmental stress and amelioration in livestock production Pp: 379-410.

42. Scholtz MM, van Zyl JP, Theunissen A (2014) The effect of epigenetic changes on animal production. Applied Animal Husbandry \& Rural Development 7(1): 7-10.

43. Bell G (2013) Evolutionary Rescue and the Limits of Adaptation. Royal Society Publisher 368(1610): 20120080. 